\title{
Topical use of MMC in the upper aerodigestive tract: a review on the side effects
}

\author{
Egbert J. D. Veen · Frederik G. Dikkers
}

Received: 15 July 2009 / Accepted: 26 October 2009 / Published online: 17 November 2009

(c) The Author(s) 2009. This article is published with open access at Springerlink.com

\begin{abstract}
Not much is known about the side effects of mitomycin $\mathrm{C}$ (MMC), an anti-fibrogenetic agent, in the upper aerodigestive tract. However, its use in ophthalmology is widely known and without quantitatively important side effects. A literature review was performed for side effects of MMC in the upper aerodigestive tract. Forty-six articles, describing the use of MMC to prevent scarring, were retracted from PubMed. Thirty-two are human studies. MMC is used in different concentrations $(0.1-10 \mathrm{mg} /$ $\mathrm{ml}$ ) with different application times (2-5 min) and frequencies (up to 4 times). Five hundred and thirty-eight patients were included in those publications, of whom 19 developed side effects $(3.53 \%)$. No side effects developed in studies, where post-application irrigation with saline was reported. The longest mean follow-up period is 75.5 months. Direct relations between the reported side effects and MMC seem absent in most studies. Serious complications seem to occur when MMC is used in high concentrations. Unfortunately, sometimes crucial information is lacking. One patient was described who supposedly developed laryngeal carcinoma after repeated treatment of hyperkeratosis and anterior commissure webbing. Animal studies show that excessive fibrin production can lead to acute airway obstruction. In conclusion, topical application of MMC on a wound with
\end{abstract}

E. J. D. Veen · F. G. Dikkers ( $\square)$

Department of Otorhinolaryngology, University Medical Center Groningen, University of Groningen, P.O. Box 30.001, 9700 RB Groningen, The Netherlands e-mail: f.g.dikkers@kno.umcg.nl

E. J. D. Veen

e-mail: e.j.d.veen@student.rug.nl consecutive irrigation with saline can be performed safely to prevent scar formation in circular structures of the upper aerodigestive tract. Long-term yearly control of the application site seems advisable.

Keywords Mitomycin C - Administration, topical $\cdot$ Side effects · Otorhinolaryngology $\cdot$ Upper aerodigestive tract

\section{Introduction}

Surgery inevitably leads to scarring. Surgery in circular structures can lead to circumferential scarring. A circumferential scar with the formation of fibrotic tissue is bound to induce complications. Mitomycin C (MMC) is known and widely used as a chemotherapeutic agent. More recently, its use was realized as an application following surgery to prevent scarring in circular structures in ophthalmology and otorhinolaryngology. Not much is known about the side effects of MMC.

The first article about using MMC to reduce living cells in vitro dates from 1968 [1]. It is an antibiotic isolated from the Streptomyces caespitosus. MMC operates by disrupting base paring of DNA molecules in the G-1 phase. The G-1 phase is the first stage of the cell cycle where the amount of cytoplasm and proteins increases in preparation of the fourth stage: mitosis. By this disrupting action, it inhibits the formation of RNA and protein synthesis and in this way inhibits the proliferation of fibroblasts [1].

An additional function is the induction of apoptosis in the fibroblasts [2, 3]. Furthermore, MMC blocks angiogenesis [4]. Because of the induction of apoptosis MMC can be toxic when given as systemic treatment. As topical therapy, however, it can be of good help, as it seems not to induce systemic toxicity. 
In recent literature and clinical practice, there is still no consensus whether it is safe or not to use MMC, concerning the (long term) side effects. In addition, a standard for the dosage seems to be lacking. There is research to the optimal dose-effect relation, but still there are conflicts of results [5].

In ophthalmology, the use of MMC has proved to positively contribute treatment regimes. In ocular and lacrimal duct surgery, MMC is known as a chemostatic agent $[6,7]$. However, it is not free of local side effects. Khong and Muecke stated that $34 \%$ of the population developed an allergic reaction, and $14 \%$ of their patients developed epiphora as a result of punctal stenosis [6]. One patient developed ptosis as a result of eye-lid edema. Despite these side effects, Khong and Muecke state that MMC is safe to use and that no serious complications were observed [6].

Currently, MMC is more and more used as an antifibrotic agent $[8,9]$. In a randomized clinical trial (RCT), Tabatabaie et al. used MMC after treatment of nasolacrimal duct obstruction. They found a significantly better result using MMC in comparison with a saline solution intraoperatively [8]. Only one of 88 patients developed a granuloma near the punctum of the lacrimal duct. Yildirim et al. in their RCT, found no beneficial effect of MMC after external dacryocystorhinostomy (EXT-DCR). One of 20 eyes in the MMC group developed epiphora, which was not significantly less compared with the control group [9].

In the upper aerodigestive tract, MMC is mostly used for the prevention of scarring. Consequently, this will lead to a different appreciation of side effects. Because MMC is more and more used as an anti-fibrogenetic agent in adults as well in children, it is important to present a clear view on any reported side effects and to report about its safety. The purpose of this study is to find out whether it is safe enough to use MMC topically in the upper aerodigestive tract.

\section{Materials and methods}

A search for articles about the use of MMC in the aerodigestive tract was performed in Pubmed. The search was until October 2008. The following meSH headings were used: mitomycin along with choanal atresia, glottis, larynx, nose, (o)esofagus, pharynx, stenosis or trachea.

For inclusion of studies, the following criteria were used:

- The use of MMC to prevent scar formation and/or stenosis in animals and humans after intervention in the aerodigestive tract.

- Study design had to be randomized or prospective clinical trial, case series, case reports or review.

\section{Results}

Forty-six articles could be used. These 46 consisted of 11 case reports [10-20], 9 case series [21-29], 7 prospective clinical trials [3, 30-35], 5 RCTs [36-40], 2 reviews [41, 42], 12 animal studies [4, 5, 43-52]. The first article about the topical use of MMC in the upper aerodigestive tract dates from 1998 [19]. The meSH heading "(o)esofagus" provided articles that were not contributing in the context of our study, as almost all dealt with the use of MMC as a chemotherapeutic agent for cancer.

Of the 46 selected articles, 32 are used for human population with a total number of 538 patients. Of these patients, 257 are males and 165 are females, while the gender of the remaining 116 patients is not mentioned. Of 490 patients, the age has been recorded: 137 are children $(<16$ years) and 353 are adults. The mean age was 34.8 years. A summary of the articles with the patient characteristics is shown in Table 1.

All 32 human studies used MMC topically. Different concentrations were used, ranging from 0.1 to $10 \mathrm{mg} / \mathrm{ml}$ (median 0.4, modus 0.4). The number of applications differs from 1 in most studies up to 12 times in one study (mean 1.17, median 1, modus 1).

Twenty-eight of 32 human studies mentioned application times of MMC. It ranged from 2 to $5 \mathrm{~min}$. The mean application time of all patients was $4.06 \mathrm{~min}$ (median 4 min, modus 4 and $5 \mathrm{~min}$ ). Twenty-seven out of 28 studies reported the use of cottonoid pledges or non-woven neuropatties soaked in an MMC solution were used. The last group sprinkled MMC at the operation site [35]. Eight of 28 studies reported that the operation site was irrigated with an isotonic saline solution, after the use of MMC.

The average follow-up period (which was reported in 27 of 32 studies) was 14.5 months, with a median of 18 months.

Nineteen of the 538 patients developed symptoms of local side effects. These studies are described in the section below. Not any of the side effects was reported in the studies where the wound was irrigated with a saline solution afterwards. No systemic side effects were reported (Table 1). Studies in which no side effects were reported will not be discussed in this paper.

Fourteen of all 46 studies that were researched are animal studies $(n=12)$ or reviews $(n=2)$. Four of the animal studies report side effects, and these studies will also be clarified and discussed.

Side effects in human studies

Local side effects differ depending on the anatomic area of MMC has been applied. They will, therefore, be reported in anatomical sequence. 
Table 1 MMC in the aerodigestive tract in human studies: study design, patient characteristics, application details, follow-up and side effects

\begin{tabular}{|c|c|c|c|c|c|c|c|c|c|}
\hline References & Design & $n$ & $\begin{array}{l}\text { Mean patient } \\
\text { age at start } \\
\text { MMC (years) }\end{array}$ & $\begin{array}{l}\text { Application } \\
\text { dose } \\
(\mathrm{mg} / \mathrm{mL})\end{array}$ & $\begin{array}{l}\text { MMC } \\
\text { application } \\
\text { time (min) }\end{array}$ & $\begin{array}{l}\text { Number of } \\
\text { applications }\end{array}$ & $\begin{array}{l}\text { Saline } \\
\text { irrigation } \\
(\mathrm{y} / \mathrm{n})\end{array}$ & $\begin{array}{l}\text { Follow-up } \\
\text { period } \\
\text { (months) }\end{array}$ & $\begin{array}{l}\text { Side } \\
\text { effects/ } \\
\text { complications }\end{array}$ \\
\hline Afzal [10] & Case report & 1 & 1.5 & 0.1 & 2 & 2 & $\mathrm{n}$ & 18 & None \\
\hline Agrawal [11] & Case report & 1 & 57 & 0.4 & Not reported & 1 & $\mathrm{n}$ & 36 & $\begin{array}{l}\text { Squamous cell } \\
\text { carcinoma }\end{array}$ \\
\hline Anand [36] & $\mathrm{RCT}$ & 29 & 49 & 0.5 & 5 & 1 & $\mathrm{n}$ & 15 & $\begin{array}{r}\text { Synechia/ } \\
\text { stenosis }\end{array}$ \\
\hline Chan [37] & $\mathrm{RCT}$ & 45 & 49 & 0.5 & 5 & 1 & $\mathrm{n}$ & 6 & None \\
\hline Chung [38] & $\mathrm{RCT}$ & 55 & 44.5 & 0.4 & 4 & 1 & $\mathrm{y}$ & 4.1 & None \\
\hline Dolmetsch [21] & Case series & 60 & 5.6 & 0.5 & 5 & 1 & $\mathrm{n}$ & 12.3 & None \\
\hline Gupta [30] & $\begin{array}{l}\text { Prospective } \\
\text { clinical trial }\end{array}$ & 30 & 30 & 0.4 & 4 & 1 & $\mathrm{y}$ & Not reported & None \\
\hline Hartnick [39] & $\mathrm{RCT}$ & 11 & 3.6 & 0.2 & 2 & 1 & $\mathrm{n}$ & Not reported & None \\
\hline Hueman [22] & Case series & 44 & 44.8 & $0.4-10$ & 4 & $1-4$ & $\mathrm{n}$ & Not reported & $\begin{array}{r}\text { Partial airway } \\
\text { obstruction }\end{array}$ \\
\hline Isa [23] & Case series & 4 & 40.5 & 0.4 & 4 & 1 & $\mathrm{y}$ & 31 & None \\
\hline Konstantinidis [40] & RCT & 30 & 29.5 & 0.5 & 5 & 2 & $\mathrm{y}$ & 7.2 & None \\
\hline $\operatorname{Kim}[31]$ & $\begin{array}{l}\text { Prospective } \\
\text { clinical trial }\end{array}$ & 20 & 31 & 0.4 & 5 & 1 & $\mathrm{n}$ & 13.3 & None \\
\hline Koshkareva [24] & Case series & 15 & 54 & 0.4 & Not reported & 1 & $\mathrm{n}$ & Not reported & None \\
\hline Kubba [25] & Case series & 22 & $<1$ & 2 & 2 & 1 & $\mathrm{n}$ & 7 & None \\
\hline Mathiasen [12] & Case report & 1 & 3.5 & 0.4 & 4 & 1 & $\mathrm{n}$ & 12 & None \\
\hline Monnier [13] & Case report & 4 & 1 & 2 & 2 & 1 & $\mathrm{n}$ & 24 & None \\
\hline Monoo-Kuofi [26] & Case series & 28 & 51.7 & 0.6 & 5 & $1-3$ & $\mathrm{n}$ & 22 & None \\
\hline Nouraei [27] & Case series & 31 & 47 & 1 & 3 & 1 & $\mathrm{n}$ & 14.6 & $\begin{array}{l}\text { Reduced } \\
\quad \text { free interval }\end{array}$ \\
\hline Penafiel [14] & Case report & 1 & Not reported & 0.5 & 2 & 1 & $\mathrm{n}$ & 24 & None \\
\hline Perepelitsyn [28] & Case series & 16 & Not reported & 0.4 & 4 & $1-3$ & $\mathrm{y}$ & 4 & None \\
\hline Phillips [15] & Case report & 1 & 18 & 2 & 4 & 2 & $\mathrm{n}$ & 12 & None \\
\hline Rahbar [3] & $\begin{array}{l}\text { Prospective } \\
\text { clinical trial }\end{array}$ & 15 & 5.7 & 0.4 & 4 & 1 & $\mathrm{y}$ & 18 & None \\
\hline Rahbar [32] & $\begin{array}{l}\text { Prospective } \\
\text { clinical trial }\end{array}$ & 14 & 34 & 0.4 & 4 & $1-3$ & $\mathrm{y}$ & 18 & None \\
\hline Roh [16] & Case report & 1 & 45 & 0.4 & 5 & 1 & $\mathrm{n}$ & 24 & None \\
\hline Roh [33] & $\begin{array}{l}\text { Prospective } \\
\text { clinical trial }\end{array}$ & 14 & 57.7 & 0.4 & 5 & 1 & $\mathrm{n}$ & Not reported & Glottic web \\
\hline Roh [34] & $\begin{array}{l}\text { Prospective } \\
\text { clinical trial }\end{array}$ & 17 & 41 & 0.4 & 5 & 1 & $\mathrm{y}$ & 18 & None \\
\hline Rosseneu [35] & $\begin{array}{l}\text { Prospective } \\
\text { clinical trial }\end{array}$ & 16 & 4 & 0.1 & 3.5 & $1-12$ & $\mathrm{n}$ & 60 & None \\
\hline Salvado [17] & Case report & 1 & 68 & 0.4 & 4 & 1 & $\mathrm{n}$ & 15 & None \\
\hline Unal [18] & Case report & 1 & 0.8 & 1 & 5 & 1 & $\mathrm{n}$ & 4 & None \\
\hline Valdez [29] & Case series & 6 & 50 & Not reported & Not reported & $1-2$ & $\mathrm{n}$ & 75.5 & None \\
\hline Ward [19] & Case report & 3 & 7.5 & 0.1 & 2 & 1 & $\mathrm{n}$ & 24 & None \\
\hline Zur [20] & Case report & 1 & 15 & 1 & Not reported & 2 & $\mathrm{n}$ & 33 & None \\
\hline Total & & 538 & & & & & & & \\
\hline
\end{tabular}

$M M C$ mitomycin C, $R C T$ randomized clinical trial, $a$ adult, $c$ child, $a / c$ the MMC was used on adults and children but exact data is lacking, $y$ yes, $n$ no, none no reported side effects

Anand et al. [36] performed an RCT in which they applied MMC at one side after bilateral ethmoidectomy and maxillary antrostomy. Nine of 29 patients experienced ste- nosis or synechia formation. Seven of 12 episodes of unwanted sequelae occurred on the MMC treated side. There was no statistically significant difference between the 
user and the non-user group. There were no major complications in this cohort of patients.

Hueman and Simpson treated 44 patients suffering from laryngotracheal stenosis with MMC in two different doses [22]. Eighty-five procedures with MMC were performed. A supersaturated dose of MMC $(10 \mathrm{mg} / \mathrm{ml})$ was used when a low-dose solution of MMC $(0.4 \mathrm{mg} / \mathrm{ml})$ was not effective after applying up to four times. The high-dose MMC was used in 14/85 procedures. Four patients developed complications due to severe local reaction: two children, in whom the high concentration of MMC was used, and two adults where the low-dose MMC was applied. All four patients suffered from respiratory distress, as a result of edema and debris. In one of the two children, this eventually led to expiration. The patient was known with glottic stenosis and recurrent respiratory papillomatosis that was treated with laser removal and cidofovir, followed by scar dilatation and the use of MMC. After 2 days, the child developed dyspnoea and eventually experienced a respiratory arrest. He expired 10 days later, due to local consequences in the larynx (debris and inflammation). However, in this case series, there was no significantly higher rate of complications in the high-dose group ( 2 of 14 procedures) in comparison with the low-dose group ( 2 of 71 procedures). Hueman and Simpson state that this can be a result of the small number of patients.

In a non-controlled, non-randomized study, Roh and Yoon looked for the outcome after the treatment for anterior commissure carcinomas (microsurgery with immediate MMC application $0.4 \mathrm{mg} / \mathrm{ml}$ for $5 \mathrm{~min}$ ) [33]. In 5 of 15 patients, an acceptably small web was formed. The webs did not have an influence on the vocal quality. One anterior glottic stenosis needed lysis and additional use of MMC. Eventually, no significant local side effects resulted from the MMC and no vocal fold atrophy was found in the patients with limited microsurgery [33].

Agrawal and Morrison wrote a case report about a 57year-old non-smoking and non-drinking male with a long history of chronic laryngitis with the removal of a polyp and keratosis (left vocal fold) [11]. Laryngoscopy showed a web at the anterior commissure. This was treated with microlaryngoscopy, laser and application of topical MMC $0.4 \mathrm{mg} /$ $\mathrm{ml}$. During follow-up, the patient developed a granuloma and a new anterior web occurred. This was also treated with laser. After 2.5 years, a T1aN0M0 squamous cell carcinoma on the right vocal fold developed. The carcinoma was locally resected and subsequent radiotherapy followed [11].

Nouraei et al. did a study towards the optimal treatment of post-intubation airway stenosis [27]. They compared a group of 11 patients with fresh lesions and stenoses with a group of 20 patients with mature stenoses. The first group was treated with intralesional steroids, laser, reduction in granulation tissue and balloon dilatation. The second group was treated with radial laser incision, balloon dilatation and immediate MMC application $(1 \mathrm{mg} / \mathrm{ml})$ during $3 \mathrm{~min}$. The outcome of this case series showed a statistically significant difference in intervention-free interval in favour of the nonMMC group. Fifty-five percent of the MMC group needed more than one procedure.

Side effects in animal studies

Garret et al. [45] examined the influence of MMC on vocal fold healing after micro-flap excision in a prospective controlled canine model. They treated the excision site with MMC $(0.4 \mathrm{mg} / \mathrm{ml})$ for $3 \mathrm{~min}$. The contralateral vocal folds were wounded, but not treated with MMC. After 4 weeks, 3 of the 6 dogs showed a persistent concavity in the vocal fold at the MMC treated excision site. This resulted in a negative effect on the vibratory pattern of the treated vocal folds when compared with the opposite side.

Iniguez-Cuadra et al. [48] performed a prospective, randomized, double-blind, controlled study. They induced inflammation by circumferential resection and end-to-end anastomosis of a tracheal annulus in 18 rabbits. Three treatment groups where made: topical saline (isotonic sodium chloride solution, group A), low dose $(0.2 \mathrm{mg} / \mathrm{ml}, \mathrm{B})$ and high dose $(0.5 \mathrm{mg} / \mathrm{ml}, \mathrm{C})$ topical MMC. All solutions were applied during $5 \mathrm{~min}$. After 8 weeks, the rabbits were killed. The effect of MMC was dose related. In group C, most rabbits progressed to stenosis with a decrease in airway diameter that was significantly larger than in the other two groups $(P<0.001)$. The mean percentage of maximum stenosis in group $\mathrm{C}$ was $51 \%$. In groups $\mathrm{A}$ and $\mathrm{B}$, it was 18 and $16 \%$, respectively. No significant differences in tracheal stenosis between groups A and B were observed. When compared with the other two groups, the high-dose MMC group had a significant increase in fibroproliferative tissue. The authors conclude that the topical MMC is not effective in avoiding tracheal stenosis and may provoke the opposite effect when the dose is not carefully selected.

Roh et al. [50] studied the recovering process after diode laser surgery in the posterior subglottis combined with topical treatment of a $0.4 \mathrm{mg} / \mathrm{ml}$ (group A), $10 \mathrm{mg} / \mathrm{ml} \mathrm{MMC} \mathrm{(B)}$ or saline solution (C). Either solution was randomly applied during $5 \mathrm{~min}$ in 60 rabbits. Animals were killed at 4 weeks, and gross and histologic findings were compared among different groups and ten age-matched, non-wound, normal controls (D). Thirty-two of the 60 (53\%) animals died mainly of acute airway obstruction by necrotic debris, sloughs on or cartilage collapse of the unhealed posterior subglottis during early weeks after wounding. This was higher in groups $\mathrm{A}$ and B $(67 \%)$ than in group C $(25 \%)(P=0.007)$. This resulted from the significant delay of wound healing in groups $\mathrm{A}$ and $\mathrm{B}$ when compared with group $\mathrm{C}(P=0.012)$. After 4 weeks, the surviving 28 rabbits of groups A, B and C showed a significantly decreased cross-sectional area of the scarred lumen 
in comparison to rabbits in group D. There was no statistically significant difference between the treated groups with regard to cross-sectional area, re-epithelialization or collagen deposition. Due to the significant risk of acute airway obstruction from delayed wound healing in rabbits, the authors suggest that clinicians should pay attention to the side effects of MMC, especially when it is used on exposed cartilage of the airway.

In yet another rabbit model, Roh et al. made two wounds in 60 rabbits, one in the upper trachea and one in the lower trachea [51]. The rabbits were divided into three groups. One group had both wounds as full thickness wounds on the anterior part of the trachea (A), one group had the two wounds as partial thickness wounds on the anterior part (B) and the final group had both wounds as partial thickness wounds on the circumferential mucosa (C). In each rabbit, one of the wounds was randomly treated with MMC $1 \mathrm{mg}$ / $\mathrm{ml}$ during $5 \mathrm{~min}$, the other with a saline solution. The incidence of early death was higher in groups $\mathrm{A}$ and $\mathrm{C}$ than in group B. This was mainly a result of airway obstruction at the MMC treated sites. They found comparable cross-sectional area of the lumen between in MMC and salinetreated wounds, but re-epithelization was significantly delayed in all MMC wounds. In conclusion, the authors state that MMC-treated rabbits with tracheal wounds develop a significant risk of acute airway obstruction.

\section{Discussion}

The indications for topical use of MMC are surgical wounds on areas in the human body where excessive formation of fibrosis can lead to functional impairment. The human aerodigestive tract is a good example: obstruction can be life threatening. By applying a soaked cotton pledget with MMC solution on the preferred operation site, one can use it with optimal control in location and time. There is ample discussion about immediate irrigation after treatment: $33.7 \%$ of the researched patients underwent irrigation of the operation site with a saline solution, which seems to have a positive effect on functional outcome as it prevents excessive fibrin production.

Several doses of MMC have been used. As it ranged from 0.1 to $10 \mathrm{mg} / \mathrm{ml}$, one could see that there was no gold standard. It seems that low doses are ineffective. Hartnick et al. have used $0.2 \mathrm{mg} / \mathrm{ml} \mathrm{MMC} \mathrm{for} 2 \mathrm{~min}$, applied once to prevent post-intubation stenosis in children in an RCT [39]. After 1 year, their Data Safety and Monitoring Committee advised to terminate the RCT as interim analysis showed that there was no difference in outcome. The lack of efficacy of MMC has also been expressed by other authors $[24,25,31,37]$, who used concentrations which varied from 0.4 to $2.0 \mathrm{mg} / \mathrm{ml}$.
In some studies MMC was applied more than once (Table 1). There seems to be no relation between the number of MMC applications and side effects except in the study of Hueman and Simpson [22] which will be discussed later.

Several side effects have been reported. Some studies report adhesions and discharge at the MMC treated side, but these appeared significantly less frequently than on a similar wound treated with saline solution [30]. It is a principal point of discussion whether these effects can be seen as a result of the surgery proper and are in that notion not mentioned as being a side effect of topical MMC application.

In our study, an attempt is made to look critically at the studies with reported side effects. The following remarks could be made.

The stenosis and synechia formation of the maxillary and ethmoidal sinus reported by Anand et al. [36] was of no statistically significant quantity compared with the nonMMC treated group.

Hueman and Simpson reported the death of a pediatric patient suffering from glottic stenosis and recurrent respiratory papillomatosis [22]. As mentioned before, this death occurred in a study for the treatment of laryngeal stenosis $(n=44)$ with the use of two different doses of MMC: 0.4 and $10 \mathrm{mg} / \mathrm{ml}$. Both groups showed local toxic effects of the MMC. The authors found that the complication rate was not significantly higher in the high-dose group. They stated that the unfortunate death was a result of a complex of complications. MMC was used in a $10 \mathrm{mg} / \mathrm{ml}$ concentration and the concentration was increased after four ineffective treatments (with $0.4 \mathrm{mg} / \mathrm{ml}$ ) without complications. Their study shows that excessive fibrin formation can lead to serious laryngeal obstruction. However, fibrin does not necessarily develop due to the use of MMC.

Roh and Yoon evaluated the effectiveness of topical MMC in preventing anterior glottic stenosis after transoral microresection of glottic lesions involving the anterior commissure [33]. Postoperatively, five patients (31\%) developed acceptably small webs in the anterior glottis. Significant local side effects or atrophy of the vocal folds owing to MMC were not found. It is not sure whether the MMC induced the web, or prevented the formation of a larger web: they conclude that topical MMC may be useful in preventing anterior glottic stenosis after surgery in the anterior commissure [33].

Noureai et al. compared the results of treating acute post-intubation stenotic airway lesions with the results of treating mature lesions and to assess whether early intervention improves the outcome [27]. Patients with airway lesions presenting within weeks of intubation were treated with intralesional steroids, laser reduction, and balloon dilatation. Patients with mature airway lesions were initially treated with laser, balloon dilatation, and topical MMC. The authors state that patients treated for acute 
injury required significantly fewer interventions. Their conclusion, that early treatment of acute fibro inflammatory airway lesions has the potential to favorably modify the natural history of post-intubation tracheal injury, is not related to beneficial or adverse effects of MMC.

Agrawal and Morrison reported a patient with potentially MMC related laryngeal carcinoma in a non-smoking adult [11]. The chance for this patient of developing laryngeal cancer is around 8.8 per 100,000 [53]. This patient, however, had a long medical history of chronic laryngitis, with previous removal of a laryngeal polyp and keratosis of the vocal fold excised. He appeared with anterior webbing. The authors repeatedly treated this webbing of his anterior commissure with laser, with or without application of MMC. As between 16 and 23\% patients with keratotic vocal folds with atypia will subsequently develop a carcinoma [54], the supposed MMC related carcinoma in this particular case cannot be attributed to the use of MMC.

Clinical studies with a long follow-up are lacking. As seen in Table 1, the longest mean follow-up period is 75.5 months. Here, six patients treated with MMC were followed [29]. A study to observe the long-term effects of the use of MMC is needed, an opinion that has been expressed by other authors as well $[29,42]$.

Some of the investigated animal studies do report some side effects of the MMC. These are conflicting with the results of the human studies.

Garret et al. found a decrease in healing response with a negative consequence on the vocal fold vibratory pattern in dogs after vocal fold surgery and treatment with MMC [45]. This finding is in contrast with the results of Roh and Yoon who found no influence on the vocal cord quality after treatment with MMC in humans [33]. However, the number of animals in Garrett's study (6 dogs) might be too small to draw conclusions.

All three studies on rabbits that were analyzed report that rabbits in the groups treated with MMC died earlier in comparison with control groups [48, 50, 51]. This is in contrast with the fact that all three studies report no significant airway reduction in the MMC groups compared with the saline-treated groups. Two studies reported increase in inflammation, [50, 51] and one does not [48]. This last study describes 18 rabbits in three groups, which, again, might be too small to draw conclusions. Roh's studies [50, 51] describe a sufficient amount of animals. However, no information on final wound healing is reported. Only excessive fibrin production leading to acute airway obstruction (which, of course, can be endoscopically removed) and delayed wound healing on exposed cartilage are mentioned. It is remarkable that the use of MMC causes acute airway obstruction where the purpose of its use is to reduce the forming of fibrosis. This obstruction can be a result of the early reaction. The severity of cicatricial stenosis (which can be seen as a late onset reaction) is not influenced by the use of MMC in their animal studies.

Translation of the results on animals to the human body is disputable, as the structure of the human vocal fold is different compared with animals. Therefore, the results of animal studies cannot be directly applied to humans. It can only give a direction for further research.

\section{Conclusion}

As can be concluded from the results, no systemic side effects appeared during the topical use of MMC at different sites in the aerodigestive tract. The effects that did occur can be considered as a result of debris that formed after the procedure. Concerning the effectiveness of MMC, no relation could be made with dose, number of applications or application time. Therefore, no advice can be given.

Unwanted sequelae developed in 19 patients with 519 patients remaining without any side effects. Only $3.53 \%$ of the investigated human population developed a side effect from the topical use of MMC. No side effects arose in studies where the application site was irrigated with saline afterwards application. In our opinion, these findings are no contraindication for the topical use of MMC in the aerodigestive tract.

There have been reports that high-dose MMC application on denuded cartilage or traumatized mucosa can lead to temporarily airway obstruction because of fibrin excess. This excess of fibrin can effectively be removed endoscopically. Only one case was described where laryngeal carcinoma theoretically might be attributed to the use of MMC. This potential development of laryngeal carcinoma after the use of MMC in the larynx implies that long follow-up is imperative. These findings should lead to precautions as in strict monitoring in the short-term and to a long-term follow-up.

In summary, topical application of MMC on a wound with consecutive irrigation with saline can be performed safely to prevent scar formation in circular structures of the upper aerodigestive tract. Long-term yearly control of the application site seems advisable.

Conflict of interest statement There are no conflicts of interest to be disclosed.

Open Access This article is distributed under the terms of the Creative Commons Attribution Noncommercial License which permits any noncommercial use, distribution, and reproduction in any medium, provided the original author(s) and source are credited.

\section{References}

1. Djordjevic B, Kim JH (1968) Different lethal effects of mitomycin $\mathrm{C}$ and actinomycin D during the division cycle of HeLa cells. J Cell Biol 38:477-482 
2. Hu D, Sires BS, Tong DC, Royack GA, Oda D (2000) Effect of brief exposure to mitomycin $\mathrm{C}$ on cultured human nasal mucosa fibroblasts. Ophthal Plast Reconstr Surg 16:119-125

3. Rahbar R, Jones DT, Nuss RC, Roberson DW, Kenna MA, McGill TJ, Healy GB (2002) The role of mitomycin in the prevention and treatment of scar formation in the pediatric aerodigestive tract: friend or foe? Arch Otolaryngol Head Neck Surg 128:401-406

4. Hardillo J, Vanclooster C, Delaere PR (2001) An investigation of airway wound healing using a novel in vivo model. Laryngoscope 111:1174-1182

5. Ferguson B, Gray SD, Thibeault S (2005) Time and dose effects of mitomycin $\mathrm{C}$ on extracellular matrix fibroblasts and proteins. Laryngoscope 115:110-115

6. Khong JJ, Muecke J (2006) Complications of mitomycin C therapy in 100 eyes with ocular surface neoplasia. $\mathrm{Br} \mathrm{J}$ Ophthalmol 90:819-822

7. Kopp ED, Seregard S (2004) Epiphora as a side effect of topical mitomycin C. Br J Ophthalmol 88:1422-1424

8. Tabatabaie SZ, Heirati A, Rajabi MT, Kasaee A (2007) Silicone intubation with intraoperative mitomycin $\mathrm{C}$ for nasolacrimal duct obstruction in adults: a prospective, randomized, double-masked study. Ophthal Plast Reconstr Surg 23:455-458

9. Yildirim C, Yaylali V, Esme A, Ozden S (2007) Long-term results of adjunctive use of mitomycin $\mathrm{C}$ in external dacryocystorhinostomy. Int Ophthalmol 27:31-35

10. Afzal NA, Albert D, Thomas AL, Thomson M (2002) A child with oesophageal strictures. Lancet 359:1032

11. Agrawal N, Morrison GA (2006) Laryngeal cancer after topical mitomycin C application. J Laryngol Otol 120:1075-1076

12. Mathiasen RA, Cruz RM (2005) Asymptomatic near-total airway obstruction by a cylindrical tracheal foreign body. Laryngoscope 115:274-277

13. Monnier P (2000) Prevention of cicatricial stenosis of the larynx resulting from intubation. Ned Tijdschr KNO-heelk 6:123-125

14. Penafiel A, Lee P, Hsu A, Eng P (2006) Topical mitomycin-C for obstructing endobronchial granuloma. Ann Thorac Surg 82:e22e23

15. Phillips PS, monoo-Kuofi K, Hore ID, Atherton DJ, Albert DM (2006) Successful treatment of laryngeal stenosis in laryngoonycho-cutaneous syndrome with topical mitomycin C. Pediatr Dermatol 23:75-77

16. Roh JL (2006) Application of mitomycin C after endoscopic lysis of congenital laryngeal web combined with epiglottic hypoplasia in a middle-aged man. Acta Otolaryngol 126:438-441

17. Salvado AR, Wang MB (2008) Treatment of complete nasal vestibule stenosis with vestibular stents and mitomycin C. Otolaryngol Head Neck Surg 138:795-796

18. Unal M (2004) The successful management of congenital laryngeal web with endoscopic lysis and topical mitomycin-C. Int J Pediatr Otorhinolaryngol 68:231-235

19. Ward RF, April MM (1998) Mitomycin-C in the treatment of tracheal cicatrix after tracheal reconstruction. Int J Pediatr Otorhinolaryngol 44:221-226

20. Zur KB, Putnam PE, Rutter MJ (2007) Combined retrograde and anterograde hypopharyngeal puncture and dilatation in a child with complete hypopharyngeal stenosis. Int J Pediatr Otorhinolaryngol 71:153-157

21. Dolmetsch AM, Gallon MA, Holds JB (2008) Nonlaser endoscopic endonasal dacryocystorhinostomy with adjunctive mitomycin C in children. Ophthal Plast Reconstr Surg 24:390-393

22. Hueman EM, Simpson CB (2005) Airway complications from topical mitomycin C. Otolaryngol Head Neck Surg 133:831-835

23. Isa AY, Macandie C, Irvine BW (2006) Nitinol stents in the treatment of benign proximal tracheal stenosis or tracheomalacia. J Laryngol Otol 120:32-37
24. Koshkareva Y, Gaughan JP, Soliman AM (2007) Risk factors for adult laryngotracheal stenosis: a review of 74 cases. Ann Otol Rhinol Laryngol 116:206-210

25. Kubba H, Bennett A, Bailey CM (2004) An update on choanal atresia surgery at Great Ormond Street Hospital for children: preliminary results with mitomycin C and the KTP laser. Int J Pediatr Otorhinolaryngol 68:939-945

26. Amonoo-Kuofi K, Lund VJ, Andrews P, Howard DJ (2006) The role of mitomycin $\mathrm{C}$ in surgery of the frontonasal recess: a prospective open pilot study. Am J Rhinol 20:591-594

27. Nouraei SA, Singh A, Patel A, Ferguson C, Howard DJ, Sandhu GS (2006) Early endoscopic treatment of acute inflammatory airway lesions improves the outcome of postintubation airway stenosis. Laryngoscope 116:1417-1421

28. Perepelitsyn I, Shapshay SM (2004) Endoscopic treatment of laryngeal and tracheal stenosis-has mitomycin $\mathrm{C}$ improved the outcome? Otolaryngol Head Neck Surg 131:16-20

29. Valdez TA, Shapshay SM (2002) Idiopathic subglottic stenosis revisited. Ann Otol Rhinol Laryngol 111:690-695

30. Gupta M, Motwani G (2006) Role of mitomycin C in reducing adhesion formation following endoscopic sinus surgery. J Laryngol Otol 120:921-923

31. Kim ST, Gang IG, Cha HE, Ha JS, Chung YS (2006) Effect of mitomycin $\mathrm{C}$ on the size of antrostomy after endoscopic sinus surgery. Ann Otol Rhinol Laryngol 115:673-678

32. Rahbar R, Shapshay SM, Healy GB (2001) Mitomycin: effects on laryngeal and tracheal stenosis, benefits, and complications. Ann Otol Rhinol Laryngol 110:1-6

33. Roh JL, Yoon YH (2005) Prevention of anterior glottic stenosis after transoral microresection of glottic lesions involving the anterior commissure with mitomycin C. Laryngoscope 115:10551059

34. Roh JL, Kim AY (2005) Application of mitomycin C after transoral removal of submandibular stones and sialodochoplasty. Laryngoscope 115:915-918

35. Rosseneu S, Afzal N, Yerushalmi B, Ibarguen-Secchia E, Lewindon P, Cameron D, Mahler T, Schwagten K, Kohler H, Lindley KJ, Thomson M (2007) Topical application of mitomycin-C in oesophageal strictures. J Pediatr Gastroenterol Nutr 44:336-341

36. Anand VK, Tabaee A, Kacker A, Newman JG, Huang C (2004) The role of mitomycin $\mathrm{C}$ in preventing synechia and stenosis after endoscopic sinus surgery. Am J Rhinol 18:311-314

37. Chan KO, Gervais M, Tsaparas Y, Genoway KA, Manarey C, Javer AR (2006) Effectiveness of intraoperative mitomycin C in maintaining the patency of a frontal sinusotomy: a preliminary report of a double-blind randomized placebo-controlled trial. Am J Rhinol 20:295-299

38. Chung JH, Cosenza MJ, Rahbar R, Metson RB (2002) Mitomycin $\mathrm{C}$ for the prevention of adhesion formation after endoscopic sinus surgery: a randomized, controlled study. Otolaryngol Head Neck Surg 126:468-474

39. Hartnick CJ, Hartley BE, Lacy PD, Liu J, Bean JA, Willging JP, Myer CM III, Cotton RT (2001) Topical mitomycin application after laryngotracheal reconstruction: a randomized, double-blind, placebo-controlled trial. Arch Otolaryngol Head Neck Surg 127:1260-1264

40. Konstantinidis I, Tsakiropoulou E, Vital I, Triaridis S, Vital V, Constantinidis J (2008) Intra- and postoperative application of Mitomycin $\mathrm{C}$ in the middle meatus reduces adhesions and antrostomy stenosis after FESS. Rhinology 46:107-111

41. Hirshoren N, Eliashar R (2009) Wound-healing modulation in upper airway stenosis-Myths and facts. Head Neck 31:111-126

42. Tabaee A, Brown SM, Anand VK (2007) Mitomycin C and endoscopic sinus surgery: where are we? Curr Opin Otolaryngol Head Neck Surg 15:40-43 
43. Correa AJ, Reinisch L, Sanders DL, Huang S, Deriso W, Duncavage JA, Garrett CG (1999) Inhibition of subglottic stenosis with mitomycin-C in the canine model. Ann Otol Rhinol Laryngol 108:1053-1060

44. Eliashar R, Eliachar I, Esclamado R, Gramlich T, Strome M (1999) Can topical mitomycin prevent laryngotracheal stenosis? Laryngoscope 109:1594-1600

45. Garrett CG, Soto J, Riddick J, Billante CR, Reinisch L (2001) Effect of mitomycin-C on vocal fold healing in a canine model. Ann Otol Rhinol Laryngol 110:25-30

46. Gray SD, Tritle N, Li W (2003) The effect of mitomycin on extracellular matrix proteins in a rat wound model. Laryngoscope 113:237-242

47. Ingrams DR, Volk MS, Biesman BS, Pankratov MM, Shapshay SM (1998) Sinus surgery: does mitomycin C reduce stenosis? Laryngoscope 108:883-886

48. Iniguez-Cuadra R, San Martin PJ, Iniguez-Cuadra M, Zuniga ES, Jofre PD, Gonzalez BS, Guilemany Toste JM, Iniguez-Sasso R (2008) Effect of mitomycin in the surgical treatment of tracheal stenosis. Arch Otolaryngol Head Neck Surg 134:709-714
49. Rahal A, Peloquin L, Ahmarani C (2001) Mitomycin C in sinus surgery: preliminary results in a rabbit model. J Otolaryngol $30: 1-5$

50. Roh JL, Lee YW, Park CI (2006) Can mitomycin C really prevent airway stenosis? Laryngoscope 116:440-445

51. Roh JL, Kim DH, Rha KS, Sung MW, Kim KH, Park CI (2007) Benefits and risks of mitomycin use in the traumatized tracheal mucosa. Otolaryngol Head Neck Surg 136:459-463

52. Spector JE, Werkhaven JA, Spector NC, Huang S, Page RN, Baranowski B, Luther M, McGehee B, Reinisch L (1999) Preservation of function and histologic appearance in the injured glottis with topical mitomycin-C. Laryngoscope 109:1125-1129

53. Ragin CC, Modugno F, Gollin SM (2007) The epidemiology and risk factors of head and neck cancer: a focus on human papillomavirus. J Dent Res 86:104-114

54. Zeitels SM (1995) Premalignant epithelium and microinvasive cancer of the vocal fold: the evolution of phonomicrosurgical management. Laryngoscope 105:1-51 